Review

\title{
Acinetobacter baumannii: Its Clinical Significance in Human and Veterinary Medicine
}

\author{
Francesca Paola Nocera ${ }^{1}$, Anna-Rita Attili ${ }^{2} \mathbb{D}$ and Luisa De Martino ${ }^{1, * \mathbb{D}}$ \\ 1 Department of Veterinary Medicine and Animal Production, University of Naples "Federico II", \\ 80137 Naples, Italy; francescapaola.nocera@unina.it \\ 2 School of Biosciences and Veterinary Medicine, University of Camerino, 62024 Matelica, Italy; \\ annarita.attili@unicam.it \\ * Correspondence: luisa.demartino@unina.it
}

Citation: Nocera, F.P.; Attili, A.-R.; De Martino, L. Acinetobacter baumannii: Its Clinical Significance in Human and Veterinary Medicine. Pathogens 2021, 10, 127. https:// doi.org/10.3390/pathogens10020127

Academic Editors: Angela H. Nobbs and Lawrence S. Young

Received: 8 December 2020

Accepted: 24 January 2021

Published: 27 January 2021

Publisher's Note: MDPI stays neutral with regard to jurisdictional claims in published maps and institutional affiliations.

Copyright: (c) 2021 by the authors. Licensee MDPI, Basel, Switzerland. This article is an open access article distributed under the terms and conditions of the Creative Commons Attribution (CC BY) license (https:// creativecommons.org/licenses/by/ $4.0 /)$.

\begin{abstract}
Acinetobacter baumannii is a Gram-negative, opportunistic pathogen, causing severe infections difficult to treat. The A. baumannii infection rate has increased year by year in human medicine and it is also considered as a major cause of nosocomial infections worldwide. This bacterium, also well known for its ability to form biofilms, has a strong environmental adaptability and the characteristics of multi-drug resistance. Indeed, strains showing fully resistant profiles represent a worrisome problem in clinical therapeutic treatment. Furthermore, A. baumannii-associated veterinary nosocomial infections has been reported in recent literature. Particularly, carbapenem-resistant A. baumannii can be considered an emerging opportunistic pathogen in human medicine as well as in veterinary medicine.
\end{abstract}

Keywords: Acinetobacter baumannii; human medicine; veterinary medicine; multi-drug resistance; biofilms

\section{Introduction}

Acinetobacter baumannii belongs to the family Moraxellaceae and order Pseudomonadales in the class Gammaproteobacteria, phylum Proteobacteria of Eubacteria [1,2]. The development of molecular methods in the last 10 years allowed a better identification of Acinetobacter spp. Clinically relevant species are mostly confined to the Acinetobacter calcoaceticus / Acinetobacter baumannii (ACB) complex, namely, A. baumannii, A. calcoaceticus, Acinetobacter pittii, Acinetobacter nosocomialis, and the recently added numerous other species [3-6].

However, among the ACB complex, A. baumannii is the most important for its frequently involvement in hospital outbreaks, affecting critically ill and immunocompromised individuals [7,8]. A rapid and accurate identification of A. baumannii to distinguish it from the other species of the complex is necessary for its growing clinical interest worldwide. Among the available identification methods, matrix-assisted laser desorption/ionization time-of-flight mass spectrometry (MALDI-TOF MS) results to be the most convenient, time-saving and accurate method [9]. Furthermore, expansion and improvement of the MALDI-TOF MS database have allowed to make this instrument an efficient method for identification of $A$. baumannii, A. pittii, and A. nosocomialis [10,11]. Several molecular methods, such as whole-genome sequencing (WGS), pulsed-field electrophoresis (PFGE), multilocus variable-number tandem repeat analysis (MLVA), amplified fragment length polymorphism (AFLP) analysis, RNA spacer fingerprinting, rapid amplification of polymorphic DNA (RAPD), repetitive extragenic palindromic PCR (rep-PCR), single-locus genotyping, trilocus sequence typing (3LST), and multilocus sequence typing (MLST), are generally used for genotyping [12].

Genotyping studies highlighted that a limited number of clones are responsible for most of the worldwide nosocomial outbreaks $[13,14]$. In particular, the Global Clone 1 (GC1) and 2 (GC2) have been extensively disseminated in more than 30 countries [15]. Even 
though, the spread of this bacterium in the hospital setting is well known, information about its circulation outside the hospitals are still scarce [16,17].

It is worth remembering that for about 10 years A. baumannii is considered an emerging opportunistic pathogen in human medicine as also in veterinary medicine, especially for small animals such as dogs and cats $[18,19]$.

Furthermore, A. baumannii is a member of the ESKAPE group, including six bacterial pathogens (Enterococcus faecium, Staphylococcus aureus, Klebsiella pneumoniae, Acinetobacter baumannii, Pseudomonas aeruginosa, and Enterobacter species) that are major causes of antibiotic-resistant infections and exhibiting several other virulence factors [20].

A. baumannii is a genus of Gram-negative bacteria, strictly aerobic, non-fermenting, non-motile, catalase-positive and oxidase-negative [7]. Multi-drug resistant (MDR) A. baumannii strains causing nosocomial infections with high mortality have been raising serious concerns in humans $[14,21]$.

Due to its virulence properties, MDR A. baumannii has emerged as one of the most troublesome pathogens for health care institutions globally [22]. MDR refers to strains that exhibit resistance to three or more antimicrobial drug classes, while extensively-drug resistant (XDR) or "extreme drug resistance" strains are epidemiologically significant since they show resistance to almost all approved antimicrobial agents including carbapenems [23]. Pan-drug resistance (PDR) indicates resistance to all drug classes in addition to carbapenems also colistin, and other polymyxins [24]. However, A. baumannii strains show different antibiotic susceptibilities as well as considerable epidemic potential, and its rapid diagnosis is of great significance for rational use of antibiotics and shortening of treatment course.

Several virulence factors have been identified by genomic analyses, including pilus, outer membrane porins, phospholipases, proteases, lipopolysaccharides, capsular polysaccharides, protein secretion systems, and iron-chelating systems. Some strains shared genes related to great ability to adhere to cells, to invade and survive as well as to form biofilms on abiotic surface $[25,26]$. A recent study showed that known virulence-related factors can be present in an A. baumannii strain of human origin (isolated from the blood of an infected patient) even if it exhibited susceptibility to most of the antibiotics tested [27]. Additionally, it is important to remember that $A$. baumannii virulence repertoire can affect cytotoxicity, persistence, bacterial killing, and chemotaxis [28,29].

\section{A. baumannii in Human Medicine}

A. baumannii is an important and opportunistic bacterium that plays a major role in the pathogenicity in humans and predominantly infects critically ill patients. It has been isolated from human nasal samples with rates from 54 to $92 \%$ in long-term care facilities suggesting a marked tropism to the nasal mucosa [30]. Moreover, it can adhere to the surfaces in the hospital environment and survive easily for a long time in adverse conditions. However, A. baumannii is accountable for severe hospital-acquired infections, affecting multiple anatomical sites of patients and, in particular, those hosted in intensive care units (ICUs) [31-33]. Therefore, in the ICUs is very important to well define the evaluation modalities of the infection risk and the microbial ecology through an active environmental microbiological surveillance, the investigation of bacterial isolates, and the behavioral surveillance of healthcare personnel [34].

A. baumannii mortality rate reaches $60 \%$ in vulnerable patients $[35,36]$. The most clinical manifestations include pneumonia and bacteremia [37]. A survey in U.S. hospitals showed that the majority of the A. baumannii isolates (57.6\%) were from the respiratory tract, followed by bloodstream (23.9\%) and skin or wound (9.1\%) in 2010 [38]. Furthermore, infections due to MDR A. baumannii and in particular carbapenem-resistant strains, have been associated with substantial mortality and hospital costs $[39,40]$. The risk factors for acquiring MDR isolates include recent exposure to antimicrobial agents, the use of venous or urinary catheters, severity of illness, duration of hospital stay, and recent surgery [41-45]. It has been also reported that mortality rate from invasive A. baumannii infection is high, 
especially when the isolate is resistant to carbapenems [46]. This bacterium could be transmitted through the closeness of affected patients or colonizers such as hospital surfaces and linen, and even medical equipment. In fact, contamination of respiratory support equipment, suction devices, and devices used for intravascular access are potential ways of access and transmission of infection [47].

Intriguingly, A. baumannii can be part of the bacterial microbiota of the skin. It has been demonstrated that more than $40 \%$ of healthy adults can be colonized by it on skin and mucous membranes, mainly in moist sites such as groin and toe webs; and a higher rate was observed among hospital staff members [48,49]. Trash et al. [50] have shown that, especially, the anesthesiologists can play a major role in perioperative infection control by practicing good personal hygiene and by properly disinfecting anesthetic equipment, as anesthesia providers may contribute to the risk of health-care-acquired infections.

In a recent article [51] a multivariate analysis showed that low oxygenation index and A. baumannii infection were risk factors for prognosis of severe influenza. Furthermore, the novel Coronavirus, known as SARS-CoV-2 responsible for Covid-19, seems to be associated with secondary bacterial infections of the lower respiratory tract of patients, more frequently due to A. baumannii, in particular MDR carbapemen-resistant strains [52-54]. These new findings highlight the concern of superinfection in patients affected by important viral infections and, consequently, this underlines the importance to limit the risk of infection and the spread of MDR strains overall in ICUs.

\section{A. baumannii in Veterinary Medicine}

In veterinary medicine, data regarding $A$. baumannii from animals are still scarce, even if some cases have been recently reported [55,56]. Particularly, in 2011 A. baumannii started to be described as an emerging pathogen in some European veterinary clinics [19,57]. Moreover, it cannot be excluded that animals may play a role as a reservoir of A. baumannii [58-60].

A. baumannii has been isolated from pets from various sites of infection, e.g., urinary tract infections, otitis, abscess, pneumonia, and sepsis [26,56,61,62]. However, Acinetobacter spp. can survive on canine healthy skin, where they may be potential reservoirs of infection, suggesting also the importance of rigorous hygiene, disinfection, and antisepsis in veterinary clinics and hospitals [61]. Belmonte et al., [58] reported pets (dogs and cats) as A. baumannii carriers with a prevalence of $6.5 \%$ in Reunion Island (France). Moreover, they demonstrated that most $A$. baumannii isolated strains belonged to ST25, a clonal lineage described as the one responsible for human outbreaks in Italy, Greece, and Turkey [63]. Interestingly, while the human ST25 strains appeared to be resistant to carbapenems, the veterinary isolates were susceptible to carbapenems and to almost all the tested antibiotics. It is therefore of major importance to avoid the selection and spread of MDR A. baumannii in animals as it is in humans, by implementation of epidemiological surveillance programs [58].

Interestingly, it has been reported that the cattle harbored A. baumannii, predominantly in the nose, and some bovine STs were the same ones already implicated in human infections; in conclusion, it appears clear that some STs are able to colonize both cattle and humans [64]. It has been also reported that the presence of $A$. baumannii in cattle shows a different prevalence among groups of the same species, such as dairy cows $(21.1 \%)$, beef cattle $(6.8 \%)$, and calves $(2.4 \%)$. Furthermore, a seasonal occurrence was shown with a peak between May and August [64].

It is noteworthy to mention that another important public health risk has been demonstrated in a Croatian pig farm [65] with the isolation in swine manure of $A$. baumannii strains, belonging to the ST195 within GC2 which represents the predominant clone among human clinical isolates in Europe [66].

Potential reservoirs of $A$. baumannii are also habitats occupied by wildlife and livestock birds with differences between bird species and geographical areas [67]. Poultry products as turkey and chicken raw meat represent a concern since they may play a role as vehicle for transmission of MDR A. baumannii to humans [68]. 
Evidences of genotypic studies and antimicrobial drug-resistant profiles of $A$. baumannii strains isolated from hospitalized animals suggested that these microorganisms are most likely nosocomial pathogens for animals [19]. However, A. baumannii strains, apart from being associated with infections in hospitalized cats and dogs, have been isolated from different horses hospitalized in different stables without being associated with the illness for which the horses were hospitalized [69]. In any case, overall, the first presence of Acinetobacter strains showing acquired resistance to carbapenems in horses is worrying because it may also be considered a public health hazard [69]. The companion animals, such as dogs, cats and horses are the most frequently hospitalized animals and the most relevant globally with $A$. baumannii-associated diseases [19]. In any case, the role of Acinetobacter species in diseases of hospitalized animals is largely unknown, as well as is currently unknown the natural reservoir of $A$. baumannii. The existence of an environmental reservoir outside the healthcare settings implicated in human or animal infections cannot be excluded.

Studies detected the presence of acquired carbapenemases in clinical isolates from pets, suggesting that they may be linked to human isolates [70,71]. Although the role of animals is still not clear in the dissemination of specific clones into the human community and hospitals, studies have demonstrated that similar or even identical A. baumannii clones have been identified in both settings [57]. This finding is generally limited to hospitalized animals with nosocomial infections. Thus, veterinary clinics face a great challenge regarding prevention, control, and treatment of infections with these microorganisms, similar to situations in human hospitals. It is necessary to remember that the proper hand hygiene practices, among effective control procedures, represent the key not only in human hospitals but also in veterinary hospitals. Finally, the possibility of $A$. baumannii spread from humans to animals or vice versa requires special attention. The emergence of cases of infections in companion animals associated with carbapenem-resistant isolates emphasizes the need for accurate diagnostics, because of the lack of a standard approach and specific treatment of $A$. baumannii infections in veterinary medicine.

In addition to pets, $A$. baumannii has also been isolated from other animals with different clinical signs, including rabbit, ferret, snake, rat, and duck [72]. However, it is clear that a difference between food-producing animals, wildlife animals and companion animals could be observed, and specific clones of $A$. baumannii isolated in human are almost identical to those from companion animals, whose closer vicinity favors the transmissibility of the strains. Studies on food-producing animals reported the isolation of A. baumannii strains generally susceptible to antibiotics, and described for the first time three new $b l a_{O X A-51}$ type beta-lactamase genes $\left(b l a_{O X A-148}, b l a_{O X A-149}\right.$, and $\left.b l a_{O X A-150}\right)$ isolated from bovine A. baumannii strains, which have not been found previously in human isolates [73]. Differently, the isolates recovered from pig fecal samples harbored one type of $b l a_{O X A-51}$-like (bla $a_{O X A-51}$ itself), which has already been reported in humans [73].

Particular attention deserves also cow, sheep, goat, and camel raw meat that can be sources of A. baumannii strains harboring antimicrobial resistance genes for both community and hospital settings environment, posing a potential risk to public health [74]. Therefore, higher levels of food-related inspection are needed, and further studies are required to define the exact role of this zoonotic pathogen in the food-chain.

\section{Antibiotic Resistance}

Antibiotic resistance is one of the biggest threats for public health. The emergence and spread of multidrug resistant (MDR) bacteria, due to increased and indiscriminate use of antibiotics, has concerned both human medicine and veterinary medicine. Generally, MDR bacterial strains are mostly associated with nosocomial infections and MDR strains are considered the cause of increased mortality rates. A. baumannii is well known as a major agent in nosocomial-associated infections, particularly, in ICUs of hospitals that harbor critically ill patients who are extremely vulnerable to infections. Furthermore, an increase in prevalence of MDR Acinetobacter spp. in hospitalized animals was also observed [19], and 
it was frequently diagnosed in association with infections such as urinary tract infections, abscess, pneumonia and sepsis [56,62].

It is worth noting that the transmission of antibiotic-resistant bacteria from animals to humans and vice versa is possible, especially in the case of potential zoonotic bacteria. In both cases, owners, operators in the veterinary sector or anyone who has contact with animals, could contract diseases or be spreaders of infections for the animals. Regarding to A. baumannii, strains isolated from hospitalized animals were found to be identical to those causing nosocomial infections in medical hospitals [57]. Recently we identified the same strain of $A$. baumannii in a dog and in its owner, in the first it was otitis externa-associated and in the second the strain was asymptomatically colonizing the nasal cavities [75].

The worldwide dissemination of MDR strains and their ability to acquire antibiotic resistance genes through several mechanisms of genetic recombination also led to the emergence of infections caused by pan-drug resistant strains (PDR), generating a worrisome therapeutic scenario [76,77]. Carbapenems are currently the antibiotics of choice against MDR Acinetobacter infections, but the number of $A$. baumannii strains showing resistance to carbapenems has been increasing rapidly [14] constituting the group of XDR strains. The resistance to carbapenems in A. baumannii, mostly mediated by acquired class $\mathrm{D}$ $\beta$-lactamases (mainly OXA-23; OXA-40, and OXA-58) [78], has been classified by the World Health Organization as "priority one" on the global priority list of antibiotic-resistant bacteria for research and development of new antibiotics [79].

A. baumannii is one of the most important MDR pathogens that, due to $\beta$-lactamases production, efflux pumps, decreased membrane permeability and altered target site of the antibiotics, is able to evade the most current therapeutic strategies. Van et al. [80] reported that more than $90 \%$ of the isolates were resistant to the tested $\beta$-lactamase/ $\beta$-lactamase inhibitors, cephalosporins, carbapenems, fluoroquinolones, and trimethoprim/sulfamethoxazole, and all isolates remained sensitive to colistin. Only two years later, it was possible to read from the literature about numerous strains resistant to colistin [81,82]. In veterinary farms, colistin has been used for decades overall for the treatment and prevention of Enterobacteriaceae infections, and, in human medicine, colistin is currently considered an "antibiotic of last resort" and is used in limited amounts under strict management. However, although resistance to colistin has been described to be due to point mutations [83], the complexity of colistin resistance in A. baumannii is still not entirely clear [84].

At present, the dominant problem caused by $A$. baumannii infection is the presence of numerous MDR strains in the hospital environment, which are often insensitive to carbapenems and susceptible only to colistin $[85,86]$. It should be noted that the number of studies characterizing the antimicrobial resistance mechanisms of Acinetobacter spp. of animal origin is still very low compared with the large number of studies reporting resistance genes in human isolates. In this regard, in Table 1 are summarized papers describing MDR, XDR, and PDR A. baumannii strains isolated from different animal species highlighting a major spread of the first two among pets (dogs, cats, and horses), which live more closely with humans and probably even more investigated. Among poultry, cattle and pigs, wildlife animals, slaughtered animals, only in pig farm was recently detected the presence of XDR A. baumannii strains. Of note, in Table 1, none of the scientific papers refers to PDR A. baumannii strains.

Furthermore, it is well known that several and versatile A. baumannii virulence factors, as those responsible for adhesion, colonization and invasion, may play a role in its pathogenesis, likely contributing to its ability to survive for a long time and adapt in different environments $[87,88]$. Innovative strategies such as new alternative antimicrobial therapies, phage therapy and the CRISPR Cas system (Clustered regularly interspaced short palindromic repeats) have been developed to prevent the spread of MDR strains [89].

Amaral et al. [90] reported the growth inhibition of clinical isolates of A. baumannii by oregano essential oil, used alone or in combination with polymyxin B, as a promising therapeutic alternative. In fact, there are many studies on antimicrobial activity of essential oils able to inhibit the growth of both carbapenem-resistant and carbapenem-susceptible 
A. baumannii strains [91,92]. Recent advances have also demonstrated that some essential oils might increase susceptibility of conventional antimicrobial agents [93,94].

Table 1. An overview and comparison of antimicrobial resistance profiles of Acinetobacter baumannii isolated from animals.

\begin{tabular}{|c|c|c|c|c|c|c|}
\hline Geographical Origin & Animal Species & Types of Infection & MDR * & $\mathrm{XDR}^{* *}$ & PDR *** & References \\
\hline Switzerland & Dogs, cats, and horses & Wound, pus, liver, catheter tip & $\mathrm{x}$ & - & - & [57] \\
\hline Switzerland & Dogs and cats & $\begin{array}{l}\text { Urine, abscesses, trachea, BAL, } \\
\text { nostrils, blood }\end{array}$ & $x$ & - & - & [18] \\
\hline Reunion Island (France) & Dogs and cats & Healthy carriers (skin) & - & - & - & [58] \\
\hline Germany & Dogs and cats & Hospitalized & $\mathrm{x}$ & - & - & [19] \\
\hline Germany & Cats & Urine & $\mathrm{x}$ & $\mathrm{x}$ & - & [95] \\
\hline Germany & Dogs & $\begin{array}{l}\text { Skin, hairs, nostrils, throat, trachea, } \\
\text { BAL, urine, abscesses, fistula }\end{array}$ & $x$ & $x$ & - & [70] \\
\hline France & Dogs & Mouth, rectal swabs & - & $x$ & - & [71] \\
\hline Italy & Dogs and cats & Rectal swabs & - & $x$ & - & [26] \\
\hline Japan & Dogs and cats & $\begin{array}{l}\text { Skin, pus, nasal secretions, urine, } \\
\text { mouth mucosa, eye, vagina, ear, feces }\end{array}$ & - & - & - & [56] \\
\hline UK & Dogs & Skin swabs & - & - & - & [61] \\
\hline Italy & Dog & Auricular swabs & - & - & - & [75] \\
\hline Belgium & Horses & Vascular catheters & $\mathrm{x}$ & - & - & [96] \\
\hline Germany & Cattle & $\begin{array}{l}\text { Fecal samples, nasal swabs, } \\
\text { rectal swabs }\end{array}$ & - & - & - & [64] \\
\hline Scotland & Cattle and pigs & $\begin{array}{c}\text { Healthy carriers } \\
\text { (fecal specimens, skin, nostril and } \\
\text { ear swabs) }\end{array}$ & - & - & - & [73] \\
\hline Croatia & Pigs & Manure & - & $x$ & - & [65] \\
\hline Germany and Poland & Chicken, geese, wild birds & Tracheal and rectal swabs & $\mathrm{x}$ & - & - & [67] \\
\hline Iraq & Turkey and chicken & Raw meat samples & $x$ & - & - & [68] \\
\hline Iran & $\begin{array}{l}\text { Cattle, sheep, goats, } \\
\text { camels, chickens }\end{array}$ & Raw meat samples & $x$ & - & - & [74] \\
\hline
\end{tabular}

Legend. MDR *: Multi-drug resistant, that means resistance to at least three class of drug (all cephalosporins, fluoroquinolones, aminoglycosides); XDR **: Extensively-drug resistant that means non-susceptible to $\geq 1$ agent in all but $\leq 2$ categories or MDR + resistance to carbapenems; PDR ${ }^{* * *}=$ Pan-drug resistant that means strains resistant to all antimicrobial agents or XDR + resistance to polymyxins; papers reporting strains with resistance to less than 3 different antimicrobial classes are those indicated by the symbol "-" in the MDR, XDR, and PDR columns.

\section{Biofilm Production}

Acinetobacter baumannii is also well known for its ability to form biofilms, which is considered an important virulence factor. Particularly, it has been demonstrated that A. baumannii strains are able to form biofilms on different biotic and abiotic surfaces, so that bacteria are protected against antimicrobial and antiseptic treatments and host defenses in vivo. Indeed, the ability of A. baumannii to grow as biofilms may contribute to its persistence in the hospital environments, increasing the probability of nosocomial infections and outbreaks [97,98].

In all bacteria, biofilm formation consists of a highly organized series of molecular events influenced by different cellular and environmental signals [99]. With regard to A. baumannii, nutrient and iron availability, carbon sources, growth temperatures, bacterial adhesions structures (pili, flagella, outer membrane proteins, and adhesins), quorum sensing and macromolecular secretions are some of the factors influencing biofilm production [97]. Studies on the type, strain A. baumannii ATCC 19606T, demonstrated that biofilm initiation on abiotic surfaces is principally due to the pilus production mediated by the CsuA/BABCDE usher-chaperone assembly system. Moreover, the expression of this 
operon is controlled by a two-component regulatory system formed by a sensor kinase, encoded by bfmS, and a response regulator, encoded by bfmR [100-102].

However, the information about the interaction of $A$. baumannii with biotic surfaces such as human bronchial epithelial cells are scarce. It is known that the adhesion of this pathogen to both biotic surfaces and to plastic surfaces is associated with the blaPER-1 gene [103].

Biofilm formation ability of $A$. baumannii strains can be strengthened by the presence of the O-linked protein glycosylation system. This system, firstly described in A. baumannii ATCC 17978 strain, stimulates the attachment step and boosts mature biofilm mass and density [104]. Furthermore, one of the major constituents of the biofilm exopolysaccharidic matrix is represented by the poly- $\beta-1,6-\mathrm{N}$-acetylglucosamine (PNAG). PNAG is encoded by the four genes cluster pgaABCD, harbored by almost all $A$. baumannii clinical strains [105].

In A. baumannii, as other bacterial pathogens, biofilm production represents a mechanism of resistance. Indeed, A. baumannii becomes metabolically inert in the deeper layers of biofilms to survive in unfavourable conditions. Poor penetration and the inability of antibiotics to act on metabolically inert bacteria increase its virulence [106]. MDR and PDR, as well as carbapenem-resistant $A$. baumannii strains, have become a relevant public's health threat, since they have been reported with an increasing frequency worldwide [107-109]. Interestingly, a positive correlation between biofilm formation and antimicrobial resistance in A. baumannii has been confirmed [110]. In fact, it has been demonstrated that MDR clinical A. baumannii isolates are able to produce large quantities of biofilm [103]. However, Perez et al. [111] described an inverse relationship between biofilm production and meropenem resistance in nosocomial A. baumannii isolates. Therefore, the ability to form a biofilm may clearly affect antibiotic susceptibility and clinical failure, even when the dose administered is in the susceptible range [112]. Thus, A. baumannii strains producing biofilms could be selected under antibiotic pressure, or contrariwise, A. baumannii isolates might acquire multidrug-resistant profiles within biofilm communities. In both cases, the survival and circulation chances of this important pathogen in clinical settings increase [103]. Biofilm-forming A. baumannii are isolated especially on healthcare devices, such as urinary catheters, central venous catheters, endotracheal tubes, polycarbonate, and stainless steel [113].

The treatment of biofilm-associated A. baumannii infections represents a great challenge, since this bacterium is responsible for chronic infections. Although A. baumannii biofilm production mechanisms on abiotic and biotic surfaces need further studies, alternative therapeutic approaches have been studied as valid option to the classical treatment therapies, that are often unsuccessful. Natural products such as microbial, plant, and animal metabolites appeared to be effective against $A$. baumannii infections [114-117].

Furthermore, it is known that the metal chelator EDTA is effective against biofilms produced by Staphylococcus spp., Pseudomonas spp., and Candida spp. Moreover, Lee et al. [103] demonstrated that EDTA was able to reduce of $55-65 \%$ the A. baumannii biofilm formation. However, interestingly, Gentile et al. [118] reported that biofilm-producing A. baumannii was able to overcome iron restriction effected by exogenous chelators thanks to the presence of multiple iron scavenging systems. In a study it was observed that $\mathrm{N}$-acetylcysteine in combination with fluoroquinolone showed an efficacy of $100 \%$ when used in vivo for the treatment of recurrent bronchopneumopathies caused by biofilm producer bacteria in dogs. The association with the mucolytic molecule improved and recovered from in vitro biofilm producer and antibiotic resistant $A$. calcoaceticus infection [119].

The ability of $A$. baumannii to produce biofilms is influenced by different factors, which play an important role in the interactions with the different abiotic and biotic surfaces. However, the mechanisms regulating adhesiveness and biofilm production vary among A. baumannii clinical strains and many of the molecular mechanisms are still obscure. Further studies are needed, in order to provide new information on the correlation between A. baumanii ability to adhere and produce biofilms, acquire multidrug-resistant profiles, and proclivity to cause chronic infections and outbreaks. The elucidation of these mechanisms is 
essential to achieve new therapeutic targets, leading to the introduction of new, innovative and valid antimicrobial strategies. In particular, innovative chelation-based anti-biofilm therapeutic approaches have been suggested as valid alternative approaches to ensure effective treatment options available to treat biofilm-associated $A$. baumannii infections both in human and veterinary medicine [118].

\section{Conclusions}

Antibiotic resistance is one of the biggest public health trials of our time. A. baumannii has developed a wide spectrum of antimicrobial resistance in comparison with non-baumannii species. Furthermore, antimicrobials used to treat various infectious diseases in animals may be the same or similar to those used for humans.

It is well known that one of the most effective stratagems used by bacteria to increase their survival in hostile environments is also represented by the formation of biofilms. For this reason, it is very important to find new compounds showing antimicrobial and antibiofilm properties. In recent years, several studies have been published on the latest advances in the finding of new alternatives, here mentioned. The new compounds should be studied in a transversal way given the documented diffusion of same clones in human medicine and in veterinary medicine. Thus, coming studies on clinical application of these new therapies must comply with the "One Health" approach because human health is dependent on animal health as well as ecosystem health.

The authors conclude suggesting the necessity of a high degree of attention to the possible zoonotic transmission of $A$. baumannii and to the possible human or animal infection from the environment.

Author Contributions: Writing-original draft preparation, L.D.M. and F.P.N.; writing-review and editing, L.D.M., F.P.N. and A.-R.A. All authors have read and agreed to the published version of the manuscript.

Funding: This research received no external funding.

Conflicts of Interest: The authors declare no conflict of interest.

\section{References}

1. Bouvet, P.J.M.; Grimont, P.A.D. Taxonomy of the genus Acinetobacter with the recognition of Acinetobacter baumannii sp. nov., Acinetobacter haemolyticus sp. nov., Acinetobacter johnsonii sp. nov., and Acinetobacter junii sp. nov. and emended descriptions of Acinetobacter calcoaceticus and Acinetobacter lwoffii. Int. J. Syst. Bacteriol. 1986, 36, 228-240.

2. Rossau, R.; Van Landschoot, A.; Gillis, M.; De Ley, J. Taxonomy of Moraxellaceae fam. nov., a new bacterial family to accommodate the genera Moraxella, Acinetobacter, and Psychrobacter and related organisms. Int. J. Syst. Bacteriol. 1991, 41, 310-329. [CrossRef]

3. Nemec, A.; Krizova, L.; Maixnerova, M.; van der Reijden, T.J.; Deschaght, P.; Passet, V.; Vaneechoutte, M.; Brisse, S.; Dijkshoorn, L. Genotypic and phenotypic characterization of the Acinetobacter calcoaceticus-Acinetobacter baumannii complex with the proposal of Acinetobacter pittii sp. nov. (formerly Acinetobacter genomic species 3) and Acinetobacter nosocomialis sp. nov. (formerly Acinetobacter genomic species 13TU). Res. Microbiol. 2011, 162, 393-404.

4. Marí-Almirall, M.; Cosgaya, C.; Higgins, P.G.; Van Assche, A.; Telli, M.; Huys, G.; Lievens, B.; Seifert, H.; Dijkshoorn, L.; Roca, I.; et al. MALDI-TOF/MS identification of species from the Acinetobacter baumannii (Ab) group revisited: Inclusion of the novel $A$. seifertii and A. dijkshoorniae species. Clin. Microbiol. Infect. 2017, 23, 210. [CrossRef]

5. Parte, A.C. LPSN_List of Prokaryotic names with Standing in Nomenclature (bacterio.net), 20 years on. Int. J. Syst. Evol. Microbiol. 2018, 68, 1825-1829. [CrossRef] [PubMed]

6. LPSN-List of Prokaryotic names with Standing in Nomenclature. Available online: https:/ /www.bacterio.net (accessed on 30 November 2020).

7. Dijkshoorn, L.; Nemec, A.; Seifert, H. An increasing threat in hospitals: Multidrug-resistant Acinetobacter baumannii. Nat. Rev. Microbiol. 2007, 5, 939-951. [CrossRef] [PubMed]

8. Peleg, A.Y.; Seifert, H.; Paterson, D.L. Acinetobacter baumannii: Emergence of a successful pathogen. Clin. Microbiol. Rev. 2008, 21, 538-582. [CrossRef]

9. Lasserre, C.; De Saint Martin, L.; Cuzon, G.; Bogaerts, P.; Lamar, E.; Glupczynski, Y.; Naas, T.; Didier Tandé, D. Efficient detection of carbapenemase activity in Enterobacteriaceae by matrix-assisted laser desorption ionization-time of flight mass spectrometry in less than 30 minutes. J. Clin. Microbiol. 2015, 53, 2163-2171. [CrossRef] 
10. Toh, B.E.; Paterson, D.L.; Kamolvit, W.; Zowawi, H.; Kvaskoff, D.; Sidjabat, H.; Wailan, A.; Peleg, A.Y.; Huber, C.A. Species identification within Acinetobacter calcoaceticus-baumannii complex using MALDI-TOF MS. J. Microbiol. Methods 2015, 118, 128-132. [CrossRef]

11. Jeong, S.; Hong, J.S.; Kim, J.O.; Kim, K.H.; Lee, W.; Bae, I.K.; Lee, K.; Jeong, S.H. Identification of Acinetobacter species using matrix-assisted laser desorption ionization-time of flight mass spectrometry. Ann. Lab. Med. 2016, 36, 325-334. [CrossRef]

12. Rafei, R.; Osman, M.; Dabboussi, F.; Hamze, M. Update on the epidemiological typing methods for Acinetobacter baumannii. Future Microbiol. 2019, 14, 1065-1080. [CrossRef] [PubMed]

13. Diancourt, L.; Passet, V.; Nemec, A.; Dijkshoorn, L.; Brisse, S. The population structure of Acinetobacter baumannii: Expanding multiresistant clones from an ancestral susceptible genetic pool. PLoS ONE 2010, 5, e10034. [CrossRef] [PubMed]

14. Higgins, P.G.; Dammhayn, C.; Hackel, M.; Seifert, H. Global spread of carbapenem resistant Acinetobacter baumannii. J. Antimicrob. Chemother. 2010, 65, 233-238. [CrossRef] [PubMed]

15. Karah, N.; Sundsfjord, A.; Towner, K.; Samuelsen, $\varnothing$. Insights into the global molecular epidemiology of carbapenem nonsusceptible clones of Acinetobacter baumannii. Drug Resist. Updates 2012, 15, 237-247. [CrossRef] [PubMed]

16. Towner, K.J. Acinetobacter: An old friend, but a new enemy. J. Hosp. Infect. 2009, 73, 355-363. [CrossRef] [PubMed]

17. Eveillard, M.; Kempf, M.; Belmonte, O.; Pailhoriès, H.; Joly-Guillou, M.L. Reservoirs of Acinetobacter baumannii outside the hospital and potential involvement in emerging human community-acquired infections. Int. J. Infect. Dis. 2013, 17, e802-e805. [CrossRef]

18. Francey, T.; Gaschen, F.; Nicolet, J.; Burnens, A.P. The role of Acinetobacter baumannii as a nosocomial pathogen for dogs and cats in an intensive care unit. J. Vet. Intern. Med. 2000, 14, 177-183. [CrossRef]

19. Zordan, S.; Prenger-Berninghoff, E.; Weiss, R.; van der Reijden, T.; van den Broek, P.; Baljer, G.; Dijkshoorn, L. Multidrug-resistant Acinetobacter baumannii in veterinary clinics, Germany. Emerg. Infect. Dis. 2011, 17, 1751-1754. [CrossRef]

20. Rice, L.B. Federal funding for the study of antimicrobial resistance in nosocomial pathogens: No ESKAPE. J. Infect. Dis. 2008, 197, 1079-1081. [CrossRef]

21. Perez, F.; Endimiani, A.; Ray, A.J.; Decker, B.K.; Wallace, C.J.; Hujer, K.M.; Ecker, D.J.; Adams, M.D.; Toltzis, P.; Dul, M.J.; et al. Carbapenem-resistant Acinetobacter baumannii and Klebsiella pneumoniae across a hospital system: Impact of post-acute care facilities on dissemination. J. Antimicrob. Chemother. 2010, 65, 1807-1818. [CrossRef]

22. Takoi, H.; Fujita, K.; Hyodo, H.; Matsumoto, M.; Otani, S.; Gorai, M.; Mano, Y.; Saito, Y.; Seike, M.; Furuya, N.; et al. Acinetobacter baumannii can be transferred from contaminated nitrile examination gloves to polypropylene plastic surfaces. Am. J. Infect. Control 2019, 47, 1171-1175. [CrossRef] [PubMed]

23. Manchanda, V.; Sanchaita, S.; Singh, N.P. Multidrug resistant Acinetobacter. J. Glob. Infect. Dis. 2010, 2, 291-304. [CrossRef] [PubMed]

24. Lee, C.M.; Lim, H.K.; Liu, C.P.; Tseng, H.K. Treatment of pan-drug resistant Acinetobacter baumannii. Scand. J. Infect. Dis. 2005, 37, 195-199. [CrossRef] [PubMed]

25. Ambrosi, C.; Scribano, D.; Aleandri, M.; Zagaglia, C.; Di Francesco, L.; Putignani, L.; Palamara, A.T. Acinetobacter baumannii virulence traits: A comparative study of a novel sequence type with other italian endemic international clones. Front. Microbiol. 2017, 8, 1977. [CrossRef] [PubMed]

26. Gentilini, F.; Turba, M.E.; Pasquali, F.; Mion, D.; Romagnoli, N.; Zambon, E.; Terni, D.; Peirano, G.; Pitout, J.D.D.; Parisi, A.; et al. Hospitalized pets as a source of carbapenem-resistance. Front. Microbiol. 2018, 9, 2872. [CrossRef]

27. Ramirez, M.S.; Penwell, W.F.; Traglia, G.M.; Zimbler, D.L.; Gaddy, J.A.; Nikolaidis, N.; Arivett, B.A.; Adams, M.D.; Bonomo, R.A.; Actis, L.A.; et al. Identification of potential virulence factors in the model strain Acinetobacter baumannii A118. Front. Microbiol. 2019, 10, 1599. [CrossRef]

28. Rodman, N.; Martinez, J.; Fung, S.; Nakanouchi, J.; Myers, A.L.; Harris, C.M.; Dang, E.; Fernandez, J.S.; Liu, C.; Mendoza, A.M.; et al. Human Pleural Fluid Elicits Pyruvate and Phenylalanine Metabolism in Acinetobacter baumannii to Enhance Cytotoxicity and Immune Evasion. Front. Microbiol. 2019, 10, 1581. [CrossRef]

29. Martinez, J.; Fernandez, J.S.; Liu, C.; Hoard, A.; Mendoza, A.; Nakanouchi, J.; Rodman, N.; Courville, R.; Tuttobene, M.R.; Lopez, C.; et al. Human pleural fluid triggers global changes in the transcriptional landscape of Acinetobacter baumannii as an adaptive response to stress. Sci. Rep. 2019, 9, 17251. [CrossRef]

30. Liu, W.J.; Zou, R.; Hu, Y.; Zhao, M.; Quan, C.; Tan, S.; Luo, K.; Yuan, J.; Zheng, H.; Liu, J. Clinical, immunological and bacteriological characteristics of H7N9 patients nosocomially co-infected by Acinetobacter baumannii: A case control study. BMC Infect. Dis. 2018, 18, 664. [CrossRef]

31. Wieczorek, P.; Sacha, P.; Hauschild, T.; Zórawski, M.; Krawczyk, M.; Tryniszewska, E. Multidrug resistant Acinetobacter baumanniithe role of AdeABC (RND family) efflux pump in resistance to antibiotics. Folia Histochem. Cytobiol. 2008, 46, 257-267. [CrossRef]

32. Bialvaei, A.Z.; Samadi Kafil, H. Colistin, mechanisms and prevalence of resistance. Curr. Med. Res. Opin. 2015, 31, 707-721. [CrossRef] [PubMed]

33. Mullié, C.; Bouharkat, B.; Guiheneuf, R.; Serra, C.; Touil-Meddah, A.T.; Sonnet, P. Efflux pumps in Acinetobacter baumannii: Role in antibiotic resistance and interest of efflux pump inhibitors as additional therapeutic weapons. In Antimicrobial Research: Novel Bioknowledge and Educational Programs; Méndez-Vilas, A., Ed.; Formatex Research Center: Badajoz, Spain, 2017. 
34. Migliara, G.; Di Paolo, C.; Barbato, D.; Baccolini, V.; Salerno, C.; Nardi, A.; Alessandri, F.; Giordano, A.; Tufi, D.; Marinelli, L.; et al. Multimodal surveillance of healthcare associated infections in an intensive care unit of a large teaching hospital. Ann. Ig. 2019, 31, 399-413. [PubMed]

35. Blanchard, C.; Barnett, P.; Perlmutter, J.; Dunman, P.M. Identification of Acinetobacter baumannii serum-associated antibiotic efflux pump inhibitors. Antimicrob. Agents Chemother. 2014, 58, 6360-6370. [CrossRef] [PubMed]

36. Zahedi Bialvaei, A.; Samadi Kafil, H.; Ebrahimzadeh Leylabadlo, H.; Asgharzadeh, M.; Aghazadeh, M. Dissemination of carbapenemases producing Gram negative bacteria in the Middle East. Iran. J. Microbiol. 2015, 7, 226-246. [PubMed]

37. Karageorgopoulos, D.E.; Falagas, M.E. Current control and treatment of multidrug-resistant Acinetobacter baumannii infections. Lancet Infect. Dis. 2008, 8, 751-762. [CrossRef]

38. Queenan, A.M.; Pillar, C.M.; Deane, J.; Sahm, D.F.; Lynch, A.S.; Flamm, R.K.; Peterson, J.; Davies, T.A. Multidrug resistance among Acinetobacter spp. in the USA and activity profile of key agents: Results from CAPITAL Surveillance 2010. Diagn. Microbiol. Infect. Dis. 2012, 73, 267-270. [CrossRef]

39. Lautenbach, E.; Synnestvedt, M.; Weiner, M.G.; Bilker, W.B.; Vo, L.; Schein, J.; Kim, M. Epidemiology and impact of imipenem resistance in Acinetobacter baumannii. Infect. Control Hosp. Epidemiol. 2009, 30, 1186-1192. [CrossRef]

40. Neidell, M.J.; Cohen, B.; Furuya, Y.; Hill, J.; Jeon, C.Y.; Glied, S.; Larson, E.L. Costs of healthcare- and community-associated infections with antimicrobial-resistant versus antimicrobial-susceptible organisms. Clin. Infect. Dis. 2012, 55, 807-815. [CrossRef]

41. Lee, S.O.; Kim, N.J.; Choi, S.H.; Hyong Kim, T.; Chung, J.W.; Woo, J.H.; Ryu, J.; Kim, Y.S. Risk factors for acquisition of imipenem-resistant Acinetobacter baumannii: A case-control study. Antimicrob. Agents Chemother. 2004, 48, 224-228. [CrossRef]

42. Cisneros, J.M.; Rodríguez-Baño, J.; Fernández-Cuenca, F.; Ribera, A.; Vila, J.; Pascual, A.; Martínez-Martínez, L.; Bou, G.; Pachón, J. Spanish Group for Nosocomial Infection (GEIH) for the Spanish Society of Infectious Diseases and Clinical Microbiology (SEIMC). Risk-factors for the acquisition of imipenem-resistant Acinetobacter baumannii in Spain: A nationwide study. Clin. Microbiol. Infect. 2005, 11, 874-879. [CrossRef]

43. Sheng, W.H.; Liao, C.H.; Lauderdale, T.L.; Ko, W.C.; Chen, Y.S.; Liu, J.W.; Lau, Y.J.; Wang, L.H.; Liu, K.S.; Tsai, T.Y.; et al. A multicenter study of risk factors and outcome of hospitalized patients with infections due to carbapenem-resistant Acinetobacter baumannii. Int. J. Infect. Dis. 2010, 14, e764-e769. [CrossRef]

44. Ng, T.M.; Teng, C.B.; Lye, D.C.; Apisarnthanarak, A. A multicenter case-case control study for risk factors and outcomes of extensively drug-resistant Acinetobacter baumannii bacteremia. Infect. Control Hosp. Epidemiol. 2014, 35, 49-55. [CrossRef] [PubMed]

45. Islahi, S.; Ahmad, F.; Khare, V.; Yaqoob, S.; Shukla, P.; Singh, Y. Incidence and risk factors associated with Acinetobacter species infection in hospitalised patients in a tertiary care hospital in North-India. J. Commun. Dis. 2015, 46, 10-12.

46. Lemos, E.V.; de la Hoz, F.P.; Einarson, T.R.; McGhan, W.F.; Quevedo, E.; Castañeda, C.; Kawai, K. Carbapenem resistance and mortality in patients with Acinetobacter baumannii infection: Systematic review and meta-analysis. Clin. Microbiol. Infect. 2014, 20, 416-423. [CrossRef] [PubMed]

47. Jung, J.; Park, W. Acinetobacter species as model microorganisms in environmental microbiology: Current state and perspectives. Appl. Microbiol. Biotechnol. 2015, 99, 2533-2548. [CrossRef]

48. Marchaim, D.; Navon-Venezia, S.; Schwartz, D.; Tarabeia, J.; Fefer, I.; Schwaber, M.J.; Carmeli, Y. Surveillance cultures and duration of carriage of multidrug-resistant Acinetobacter baumannii. J. Clin. Microbiol. 2007, 45, 1551-1555. [CrossRef] [PubMed]

49. Morgan, D.J.; Liang, S.Y.; Smith, C.L.; Johnson, J.K.; Harris, A.D.; Furuno, J.P.; Thom, K.A.; Snyder, G.M.; Day, H.R.; Perencevich, E.N. Frequent multidrug-resistant Acinetobacter baumannii contamination of gloves, gowns, and hands of healthcare workers. Infect. Control Hosp. Epidemiol. 2010, 31, 716-721. [CrossRef] [PubMed]

50. Tash, R.M.E.; Wegdan, A.A.; Amer, F.A.; Bassyouni, R.H.A.; Botros, J.M. Pattern of anaesthetic equipment contamination and infection prevention in anaesthesia practice at university hospitals. Indian J. Anaesth. 2018, 62, 786-792. [CrossRef]

51. Qin, H.; Li, M.; Zheng, L.; Zhao, H. Clinical characteristics and prognosis analysis of 37 patients with severe influenza. Zhonghua Wei Zhong Bing Ji Jiu Yi Xue. 2020, 32, 1253-1256.

52. Sharifipour, E.; Shams, S.; Esmkhani, M.; Khodadadi, J.; Fotouhi-Ardakani, R.; Koohpaei, A.; Doosti, Z.; Golzari, S.E.J. Evaluation of bacterial co-infections of the respiratory tract in COVID-19 patients admitted to ICU. BMC Infect. Dis. 2020, 20, 646. [CrossRef]

53. Perez, S.; Innes, G.K.; Walters, M.S.; Mehr, J.; Arias, J.; Greeley, R.; Chew, D. Increase in hospital-acquired carbapenem-resistant Acinetobacter baumannii infection and colonization in an acute care hospital during a surge in COVID-19 admissions-New Jersey, February-July 2020. MMWR Morb. Mortal Wkly. Rep. 2020, 69, 1827-1831. [CrossRef]

54. Lima, W.G.; Moreira Brito, J.C.; da Cruz Nizer, W.S. Ventilator-associated pneumonia (VAP) caused by carbapenem-resistant Acinetobacter baumannii in patients with COVID-19: Two problems, one solution? Med. Hypotheses 2020, 144, 110139. [CrossRef]

55. Müller, S.; Janssen, T.; Wieler, L.H. Multidrug resistant Acinetobacter baumannii in veterinary medicine-emergence of an underestimated pathogen? Berl. Munch. Tierarztl. Wochenschr. 2014, 127, 435-446.

56. Kimura, Y.; Harada, K.; Shimizu, T.; Sato, T.; Kajino, A.; Usui, M.; Tamura, Y.; Tsuyuki, Y.; Miyamoto, T.; Ohki, A.; et al. Species distribution, virulence factors and antimicrobial resistance of Acinetobacter spp. isolates from dogs and cats: A preliminary study: Acinetobacter spp. from dogs and cats. Microbiol. Immunol. 2018, 62, 462-466. [CrossRef]

57. Endimiani, A.; Hujer, K.M.; Hujer, A.M.; Bertschy, I.; Rossano, A.; Koch, C.; Gerber, V.; Francey, T.; Bonomo, R.A.; Perreten, V. Acinetobacter baumannii isolates from pets and horses in Switzerland: Molecular characterization and clinical data. J. Antimicrob. Chemother. 2011, 66, 2248-2254. [CrossRef] 
58. Belmonte, O.; Pailhoriès, H.; Kempf, M.; Gaultier, M.P.; Lemarié, C.; Ramont, C.; Joly-Guillou, M.L.; Eveillard, M. High prevalence of closely-related Acinetobacter baumannii in pets according to a multicentre study in veterinary clinics, Reunion Island. Vet. Microbiol. 2014, 170, 446-450. [CrossRef]

59. Kempf, M.; Rolain, J.M. Emergence of resistance to carbapenems in Acinetobacter baumannii in Europe: Clinical impact and therapeutic options. Int. J. Antimicrob. Agents 2012, 39, 105-114. [CrossRef]

60. Rafei, R.; Hamze, M.; Pailhoriès, H.; Eveillard, M.; Marsollier, L.; Joly-Guillou, M.L.; Dabboussi, F.; Kempf, M. Extrahuman epidemiology of Acinetobacter baumannii in Lebanon. Appl. Environ. Microbiol. 2015, 81, 2359-2367. [CrossRef]

61. Mitchell, K.E.; Turton, J.F.; Lloyd, D.H. Isolation and identification of Acinetobacter spp. from healthy canine skin. Vet. Dermatol. 2018, 29, 240-287. [CrossRef]

62. van der Kolk, J.H.; Endimiani, A.; Graubner, C.; Gerber, V.; Perreten, V. Acinetobacter in veterinary medicine, with an emphasis on Acinetobacter baumannii. J. Glob. Antimicrob. Resist. 2019, 16, 59-71. [CrossRef]

63. Di Popolo, A.; Giannouli, M.; Triassi, M.; Brisse, S.; Zarilli, R. Molecular epidemiological investigation of multidrug-resistant Acinetobacter baumannii strains in four Mediterranean countries with a multilocus sequence typing scheme. Clin. Microbiol. Infect. 2010, 17, 190-203. [CrossRef]

64. Klotz, P.; Higgins, P.G.; Schaubmar, A.R.; Failing, K.; Leidner, U.; Seifert, H.; Scheufen, S.; Semmler, T.; Ewers, C. Seasonal occurrence and carbapenem susceptibility of bovine Acinetobacter baumannii in Germany. Front. Microbiol. 2019, 10, 272. [CrossRef]

65. Hrenovic, J.; Seruga Music, M.; Durn, G.; Dekic, S.; Hunjak, B.; Kisic, I. Carbapenem-resistant Acinetobacter baumannii recovered from Swine Manure. Microb. Drug Resist. 2019, 25, 725-730. [CrossRef]

66. Pournaras, S.; Dafopoulou, K.; Del Franco, M.; Zarkotou, O.; Dimitroulia, E.; Protonotariou, E.; Poulou, A.; Zarrilli, R.; Sakris, A. Predominance of international clone 2 OXA-23-producing-Acinetobacter baumannii clinical isolates in Greece, 2015: Results of a nationwide study. Int. J. Antimicrob. Agents 2017, 49, 749-753. [CrossRef]

67. Wilharm, G.; Skiebe, E.; Higgins, P.G.; Poppel, M.T.; Blaschke, U.; Leser, S.; Heider, C.; Heindorf, M.; Brauner, P.; Jäckel, U.; et al. Relatedness of wildlife and livestock avian isolates of the nosocomial pathogen Acinetobacter baumannii to lineages spread in hospitals worldwide. Environ. Microbiol. 2017, 19, 4349-4364. [CrossRef]

68. Ghaffoori Kanaan, M.H.; Al-Shadeedi, S.M.J.; Al-Massody, A.J.; Ghasemian, A. Drug resistance and virulence traits of Acinetobacter baumannii from Turkey and chicken raw meat. Comp. Immunol. Microbiol. Infect. Dis. 2020, 70, 101451. [CrossRef]

69. Smet, A.; Boyen, F.; Pasmans, F.; Butaye, P.; Martens, A.; Nemec, A.; Deschaght, P.; Vaneechoutte, M.; Haesebrouck, F. OXA-23producing Acinetobacter species from horses: A public health hazard? J. Antimicrob. Chemother. 2012, 67, 3009-3014. [CrossRef]

70. Ewers, C.; Klotz, P.; Leidner, U.; Stamm, I.; Prenger-Berninghoff, E.; Göttig, S.; Semmler, T.; Scheufen, S. OXA-23 and ISAba1OXA-66 class D $\beta$-lactamases in Acinetobacter baumannii isolates from companion animals. Int. J. Antimicrob. Agents 2017, 49, 37-44. [CrossRef]

71. Hérivaux, A.; Pailhoriès, H.; Quinqueneau, C.; Lemarié, C.; Marie-Laure, J.G.; Ruvoen, N.; Eveillard, M.; Kempf, M. First report of carbapenemase-producing Acinetobacter baumannii carriage in pets from the community in France. Int. J. Antimicrob. Agents 2016, 48, 220-221. [CrossRef]

72. Wareth, G.; Neubauer, H.; Sprague, L.D. Acinetobacter baumannii-A neglected pathogen in veterinary and environmental health in Germany. Vet. Res. Com. 2019, 43, 1-6. [CrossRef]

73. Hamouda, A.; Findlay, J.; Al Hassan, L.; Amyes, S.G.B. Epidemiology of Acinetobacter baumannii of animal origin. Int. J. Antimicrob. Agents 2011, 38, 314-318. [CrossRef] [PubMed]

74. Askari, N.; Momtaz, H.; Tajbakhsh, E. Prevalence and phenotypic pattern of antibiotic resistance of Acinetobacter baumannii isolated from different types of raw meat samples in Isfahan, Iran. Vet. Med. Sci. 2020, 6, 147-153. [CrossRef] [PubMed]

75. Nocera, F.P.; Addante, L.; Capozzi, L.; Bianco, A.; Fiorito, F.; De Martino, L.; Parisi, A. Detection of a novel clone of Acinetobacter baumannii isolated from a dog with otitis externa. Comp. Immunol. Microbiol. Infect. Dis. 2020, 70, 101471. [CrossRef] [PubMed]

76. Taccone, F.S.; Rodríguez-Villalobos, H.; De Backer, D.; De Moor, V.; Deviere, J.; Vincent, J.L.; Jacobs, F. Successful treatment of septic shock due to pan-resistant Acinetobacter baumannii using combined antimicrobial therapy including tigecycline. Eur. J. Clin. Microbiol. Infect. Dis. 2006, 25, 257-260. [CrossRef]

77. Valencia, R.; Arroyo, L.A.; Conde, M.; Aldana, J.M.; Torres, M.J.; Fernández-Cuenca, F.; Garnacho-Montero, J.; Cisneros, J.M.; Ortíz, C.; Pachón, J.; et al. Nosocomial outbreak of infection with pan-drug-resistant Acinetobacter baumannii in a tertiary care university hospital. Infect. Control Hosp. Epidemiol. 2009, 30, 257-263. [CrossRef]

78. Turton, J.F.; Ward, M.E.; Woodford, N.; Kaufmann, M.E.; Pike, R.; Livermore, D.M.; Pitt, T.L. The role of ISAba1 in expression of OXA carbapenemase genes in Acinetobacter baumannii. FEMS Microbiol. Lett. 2006, 258, 72-77. [CrossRef]

79. World Health Organization. Global Priority List of Antibiotic-Resistant Bacteria to Guide Research, Discovery, and Development of New Antibiotics; World Health Organization: Geneva, Switzerland, 2017. Available online: https://www.who.int/medicines / publications / global-priority-list-antibiotic-resistant-bacteria/en/ (accessed on 27 February 2017).

80. Van, T.D.; Dinh, Q.D.; Vu, P.D.; Nguyen, T.V.; Pham, C.V.; Dao, T.T.; Phung, C.D.; Hoang, H.T.; Tang, N.T.; Do, N.T.; et al. Antibiotic susceptibility and molecular epidemiology of Acinetobacter calcoaceticus-baumannii complex strains isolated from a referral hospital in northern Vietnam. J. Glob. Antimicrob. Resist. 2014, 2, 318-321. [CrossRef]

81. Mu, X.; Wang, N.; Li, X.; Shi, K.; Zhou, Z.; Yu, Y.; Hua, X. The effect of colistin resistance-associated mutations on the fitness of Acinetobacter baumannii. Front. Microbiol. 2016, 1, 1715. [CrossRef] 
82. Rossi, F.; Girardello, R.; Cury, A.P.; Gioia, T.S.; Almeida, J.N., Jr.; Duarte, A.J. Emergence of colistin resistance in the largest university hospital complex of São Paulo, Brazil, over five years. Braz. J. Infect. Dis. 2017, 21, 98-101. [CrossRef]

83. Nhu, N.T.K.; Riordan, D.W.; Nhu, T.D.H.; Thanh, D.P.; Thwaites, G.; Lan, N.P.H.; Wren, B.W.; Baker, S.; Stabler, R.A. The induction and identification of novel colistin resistance mutations in Acinetobacter baumannii and their implications. Sci. Rep. 2016, 6, 28291.

84. Gerson, S.; Betts, J.W.; Lucaßen, K.; Nodari, C.S.; Wille, J.; Josten, M.; Göttig, S.; Nowak, J.; Stefanik, D.; Roca, I.; et al. Investigation of novel pmrB and eptA mutations in isogenic Acinetobacter baumannii isolates associated with colistin resistance and increased virulence in vivo. Antimicrob. Agents Chemother. 2019, 63, e01586-18. [CrossRef]

85. Mastoraki, A.; Douka, E.; Kriaras, I.; Stravopodis, G.; Saroglou, G.; Geroulanos, S. Preventing strategy of multidrug-resistant Acinetobacter baumannii susceptible only to colistin in cardiac surgical intensive care units. Eur. J. Cardiothorac. Surg. 2008, 33, 1086-1090. [CrossRef]

86. Tripathi, P.C.; Gajbhiye, S.R.; Agrawal, G.N. Clinical and antimicrobial profile of Acinetobacter spp.: An emerging nosocomial superbug. Adv. Biomed. Res. 2014, 9, 13. [CrossRef]

87. Eijkelkamp, B.A.; Stroeher, U.H.; Hassan, K.A.; Paulsen, I.T.; Brown, M.H. Comparative analysis of surface-exposed virulence factors of Acinetobacter baumannii. BMC Gen. 2014, 15, 1020. [CrossRef]

88. Momtaz, H.; Seifati, S.M.; Tavakol, M. Determining the prevalence and detection of the most prevalent virulence genes in Acinetobacter baumannii isolated from hospital infections. Int. J. Med. Lab. 2015, 2, 87-97.

89. Vrancianu, C.O.; Gheorghe, I.; Barbu Czobor, I.; Chifiriuc, M.C. Antibiotic resistance profiles, molecular mechanisms and innovative treatment strategies of Acinetobacter baumannii. Microorganisms 2020, 8, 935. [CrossRef]

90. Amaral, S.C.; Pruski, B.B.; de Freitas, S.B.; Allend, S.O.; Ferreira, M.R.A.; Moreira, C., Jr.; Pereira, D.I.B.; Junior, A.S.V.; Hartwig, D.D. Origanum vulgare essential oil: Antibacterial activities and synergistic effect with polymyxin B against multidrug-resistant Acinetobacter baumannii. Mol. Biol. Rep. 2020, 47, 9615-9625. [CrossRef]

91. Abdolrahimzadeh, H.; Bolandparvaz, S.; Abbasi, H.R.; Dehghankhalili, M.; Paydar, S.; Dehghanian, A.; Hafez Ghoran, S.; Asadollahi, M.; Zare, M. Antimicrobial survey of local herbal drugs against Acinetobacter baumannii isolated from patients admitted to a level-I trauma center. Bull. Emerg. Trauma 2018, 6, 355-362. [CrossRef]

92. Vasconcelos, N.G.; Croda, J.; Silva, K.E.; Motta, M.L.L.; Maciel, W.G.; Limiere, L.C.; Simionatto, S. Origanum vulgare L. essential oil inhibits the growth of carbapenem-resistant gram-negative bacteria. Rev. Soc. Bras. Med. Trop. 2019, 52, e20180502. [CrossRef]

93. Trifan, A.; Luca, S.V.; Greige-Gerges, H.; Miron, A.; Gille, E.; Aprotosoaie, A.C. Recent advances in tackling microbial multidrug resistance with essential oils: Combinatorial and nano-based strategies. Crit. Rev. Microbiol. 2020, 46, 338-357. [CrossRef]

94. Vázquez-Ucha, J.C.; Martínez-Guitián, M.; Lasarte-Monterrubio, C.; Conde-Pérez, K.; Arca-Suárez, J.; Álvarez-Fraga, L.; Pérez, A.; Crecente-Campo, J.; Alonso, M.J.; Bou, G.; et al. Syzygium aromaticum (clove) and Thymus zygis (thyme) essential oils increase susceptibility to colistin in the nosocomial pathogens Acinetobacter baumannii and Klebsiella pneumoniae. Biomed. Pharmacother. 2020, 130, 110606. [CrossRef] [PubMed]

95. Ewers, C.; Klotz, P.; Scheufen, S.; Leidner, U.; Göttig, S.; Semmler, T. Genome sequence of OXA-23 producing Acinetobacter baumannii IHIT7853, a carbapenem-resistant strain from a cat belonging to international clone IC1. Gut Pathog. 2016, 8, 37. [CrossRef] [PubMed]

96. Vaneechoutte, M.; Devriese, L.A.; Dijkshoorn, L.; Lamote, B.; Deprez, P.; Verschraegen, G.; Haesebrouck, F. Acinetobacter baumannii-infected vascular catheters collected from horses in an equine clinic. J. Clin. Microbiol. 2000, 38, 4280-4281. [CrossRef] [PubMed]

97. Gaddy, J.A.; Actis, L.A. Regulation of Acinetobacter baumannii biofilm formation. Future Microbiol. 2009, 4, 273-278. [CrossRef] [PubMed]

98. Longo, F.; Vuotto, C.; Donelli, G. Biofilm formation in Acinetobacter baumannii. New Microbiol. 2014, 37, 119-127. [PubMed]

99. Stanley, N.R.; Lazazzera, B.A. Environmental signals and regulatory pathways that influence biofilm formation. Mol. Microbiol. 2004, 52, 917-924. [CrossRef]

100. Tomaras, A.P.; Dorsey, C.W.; Edelmann, R.E.; Actis, L.A. Attachment to and biofilm formation on abiotic surfaces by Acinetobacter baumannii: Involvement of a novel chaperone-usher pili assembly system. Microbiology 2003, 149, 3473-3484. [CrossRef]

101. Tomaras, A.P.; Flagler, M.J.; Dorsey, C.W.; Gaddy, J.A.; Actis, L.A. Characterization of a two-component regulatory system from Acinetobacter baumannii that controls biofilm formation and cellular morphology. Microbiology 2008, 154, 3398-3409. [CrossRef]

102. De Breij, A.; Gaddy, J.; van der Meer, J.; Koning, R.; Koster, A.; van den Broek, P.; Actis, L.; Nibbering, P.; Dijkshoorn, L. CsuA/BABCDE-dependent pili are not involved in the adherence of Acinetobacter baumannii ATCC19606(T) to human airway epithelial cells and their inflammatory response. Res. Microbiol. 2009, 160, 213-218. [CrossRef]

103. Lee, H.W.; Koh, Y.M.; Kim, J.; Lee, J.C.; Lee, Y.C.; Seol, S.Y.; Cho, D.T.; Kim, J. Capacity of multidrug-resistant clinical isolates of Acinetobacter baumannii to form biofilm and adhere to epithelial cell surfaces. Clin. Microbiol. Infect. 2008, 14, 49-54. [CrossRef]

104. Iwashkiw, J.A.; Seper, A.; Weber, B.S.; Scott, N.E.; Vinogradov, E.; Stratilo, C.; Reiz, B.; Cordwell, S.J.; Whittal, R.; Schild, S.; et al Identification of a general O-linked protein glycosylation system in Acinetobacter baumannii and its role in virulence and biofilm formation. PLoS Pathog. 2012, 8, e1002758. [CrossRef] [PubMed]

105. Choi, A.H.; Slamti, L.; Avci, F.Y.; Pier, G.B.; Maira-Litrán, T. The pgaABCD locus of Acinetobacter baumannii encodes the production of poly-beta-1-6-N-acetylglucosamine, which is critical for biolfilm formation. J. Bacteriol. 2009, 191, 5953-5963. [CrossRef] [PubMed] 
106. Greene, C.; Wu, J.; Rickard, A.H.; Xi, C. Evaluation of the ability of Acinetobacter baumannii to form biofilms on six different biomedical relevant surfaces. Lett. Appl. Microbiol. 2016, 63, 233-239. [CrossRef] [PubMed]

107. Vahaboglu, H.; Coskunkan, F.; Tansel, O.; Ozturk, R.; Sahin, N.; Koksal, I.; Kocazeybek, B.; Tatman-Otkun, M.; Leblebicioglu, H.; Ozinel, M.A.; et al. Clinical importance of extended-spectrum $\beta$-lactamase (PER-1 type)—producing Acinetobacter spp. and Pseudomonas aeruginosa strains. J. Med. Microbiol. 2001, 50, 642-645. [CrossRef] [PubMed]

108. Hsueh, P.R.; Teng, L.J.; Chen, C.Y.; Chen, W.H.; Yu, C.J.; Ho, S.W.; Luh, K.T. Pandrug-resistant Acinetobacter baumannii causing nosocomial infections in a veterinary hospital, Taiwan. Emerg. Infect. Dis. 2002, 8, 827-832. [CrossRef]

109. Abbo, A.; Navon-Venezia, S.; Hammer-Muntz, O.; Krichali, T.; Siegma-Igra, Y.; Carmeli, Y. Multidrug-resistant Acinetobacter baumannii. Emerg. Infect. Dis. 2005, 11, 22-29. [CrossRef]

110. Badave, G.K.; Kulkarni, D. Biofilm producing multidrug resistant Acinetobacter baumannii: An emerging challenge. J. Clin. Diagn. Res. 2015, 9, DC08-DC10. [CrossRef]

111. Perez, L.R. Acinetobacter baumannii displays inverse relationship between meropenem resistance and biofilm production. J. Chemother. 2015, 27, 13-16. [CrossRef]

112. Kim, H.A.; Ryu, S.Y.; Seo, I.; Suh, S.I.; Suh, M.H.; Baek, W.K. Biofilm formation and colistin susceptibility of Acinetobacter baumannii isolated from Korean nosocomial samples. Microb. Drug Resist. 2015, 21, 452-457. [CrossRef]

113. Harding, C.M.; Hennon, S.W.; Feldman, M.F. Uncovering the mechanisms of Acinetobacter baumannii virulence. Nat. Rev. Microbiol. 2018, 16, 91-102. [CrossRef]

114. Peng, L.; DeSousa, J.; Su, Z.; Novak, B.M.; Nevzorov, A.A.; Garland, E.R.; Melander, C. Inhibition of Acinetobacter baumannii biofilm formation on a methacrylate polymer containing a 2-aminoimidazole subunit. Chem. Commun. 2011, 47, 4896-4898. [CrossRef] [PubMed]

115. Seo, H.; Kim, J.; Jung, J.; Jin, H.M.; Jeon, C.O.; Park, W. Complexity of cell-cell interactions between Pseudomonas sp. AS1 and Acinetobacter oleivorans DR1: Metabolic commensalism, biofilm formation and quorum quenching. Res. Microbiol. 2012, 163, 173-181. [CrossRef] [PubMed]

116. Tutar, U. Study of the Effect of Essential Oil of Salvia glutinosa L. on Microbial Biofilm Formation by Clinical Isolates of Acinetobacter baumannii. In AIP Conference Proceedings; AIP Publishing: Antalya, Turkey, 2016.

117. Gordya, N.; Yakovlev, A.; Kruglikova, A.; Tulin, D.; Potolitsina, E.; Suborova, T.; Bordo, D.; Rosano, C.; Chernysh, S. Natural antimicrobial peptide complexes in the fighting of antibiotic resistant biofilms: Calliphora vicina medicinal maggots. PLoS ONE 2017, 12, e0173559. [CrossRef] [PubMed]

118. Gentile, V.; Frangipani, E.; Bonchi, C.; Minandri, F.; Runci, F.; Visca, P. Iron and Acinetobacter baumannii biofilm formation. Pathogens 2014, 3, 704-719. [CrossRef] [PubMed]

119. Attili, A.R.; Cerquetella, M.; Pampurini, F.; Laus, F.; Spaterna, A.; Cuteri, V. Association between Enrofloxacin and NAcetylcysteine in recurrent bronchopneumopathies in dogs caused by biofilm producer bacteria. J. Anim. Vet. Adv. 2012, $11,462-469$. 